\title{
Malignant Cecum Neoplasm
}

National Cancer Institute

\section{Source}

National Cancer Institute. Malignant Cecum Neoplasm. NCI Thesaurus. Code C9329.

A primary or metastatic malignant neoplasm that affects the cecum. Representative examples include carcinoma, lymphoma, and sarcoma. 